\title{
Cyclosporine A-related neurotoxicity after haploidentical hematopoietic stem cell transplantation in children with hematopathy
}

Yong Wang ${ }^{1 \dagger}$, Yongzhi Zheng ${ }^{2 \dagger}$, Jingjing Wen ${ }^{2}$, Jinhua Ren ${ }^{2}$, Xiaohong Yuan ${ }^{2}$, Ting Yang ${ }^{2 *}$ and Jianda $\mathrm{Hu}^{2^{*}}$

\begin{abstract}
Background: To evaluate cyclosporine A (CSA)-related neurotoxicity after haploidentical hematopoietic stem cell transplantation (HID-HSCT) in children with hematopathy.

Methods: This retrospective case series study included children with hematopathy who underwent HID-HSCT at Fujian Medical University Union Hospital between February 2013 and January 2017.

Results: Fifty-one children (39 males) were included in the study with a median age of 8 (range, 1.1-18) years. Seven patients (13.7\%) developed CSA-related neurotoxicity after a median 38 (range, -3 to 161) days from HIDHSCT. Hypertension $(5 / 7,71 \%)$ was the most common prodrome. Brain magnetic resonance imaging showed posterior reversible encephalopathy syndrome in six patients and atypical abnormalities in one patient. One patient died from grade IV graft-versus-host disease (GVHD) on day + 160, and six patients were alive at the last follow-up. Four patients (71.4\%) achieved complete remission, while two patients developed secondary epilepsy and exhibited persistent MRI and electroencephalogram abnormalities at the 5-year follow-up. Hypertension after CSA was more common in patients with CSA-related neurotoxicity than in those without ( $71 \% \mathrm{vs.} 11 \%, P=0.002)$. Five-year overall survival did not differ significantly between patients with CSA-related neurotoxicity $(85.7 \pm 13.2 \%)$ and those without $(65.8 \pm 7.2 \%)$.
\end{abstract}

Conclusions: The incidence of CSA-related neurotoxicity in children with hematopathy undergoing HID-HSCT is relatively high.

Keywords: Cyclosporine a, Neurotoxicity syndrome, Hematopoietic stem cell transplantation, Child, Hematopathy

\section{Background}

Hematopoietic stem cell transplantation (HSCT) is the most effective curative therapy for a variety of hematological disorders [1]. Excitingly, the success of haploidentical HSCT (HID-HSCT) has ushered in a new

\footnotetext{
* Correspondence: yang.hopeting@gmail.com; drjiandahu@163.com †Yong Wang and Yongzhi Zheng contributed equally to this work. ${ }^{2}$ Department of Hematology, Fujian Institute of Hematology, Fujian Provincial Key Laboratory of Hematology, Fujian Medical University Union Hospital, No. 29 Xinquan Road, Gulou District, Fuzhou City, Fujian Province, China Full list of author information is available at the end of the article
}

era wherein "everyone has a donor" [2]. The number of children with hematopathy who undergo HID-HSCT has increased dramatically in China, where donor sourcing has been complex because the former one-child policy resulted in sibling donors being a relative rarity [3]. However, the success of HSCT is restricted by graftversus-host disease (GvHD), a serious complication that affects quality of life and is the main cause of death after transplantation $[4,5]$. Prophylaxis against GvHD usually involves the administration of a calcineurin inhibitor,

C C The Author(s). 2021 Open Access This article is licensed under a Creative Commons Attribution 4.0 International License, which permits use, sharing, adaptation, distribution and reproduction in any medium or format, as long as you give appropriate credit to the original author(s) and the source, provide a link to the Creative Commons licence, and indicate if changes were made. The images or other third party material in this article are included in the article's Creative Commons licence, unless indicated otherwise in a credit line to the material. If material is not included in the article's Creative Commons licence and your intended use is not permitted by statutory regulation or exceeds the permitted use, you will need to obtain permission directly from the copyright holder. To view a copy of this licence, visit http://creativecommons.org/licenses/by/4.0/. The Creative Commons Public Domain Dedication waiver (http://creativecommons.org/publicdomain/zero/1.0/) applies to the data made available in this article, unless otherwise stated in a credit line to the data. 
such as cyclosporine A (CSA) or tacrolimus, together with an immunosuppressant, such as low-dose methotrexate or mycophenolate, although alternative agents are also available [6].

CSA is the cornerstone of GvHD prophylaxis. However, neurotoxicity is one of the most common early complications occurring with CSA usage in clinical practice because CSA has a narrow therapeutic index and large inter-individual and intra-individual variability in its pharmacokinetics $[7,8]$. Neurotoxicity occurs in 5$11 \%$ of patients receiving CSA as GvHD prophylaxis after HSCT [9-13]. The presentation of CSA-related neurotoxicity includes impaired consciousness, seizures, visual disturbance, headache, involuntary movements and paresis [9-14]. Magnetic resonance imaging (MRI) usually shows radiologic features of posterior reversible encephalopathy syndrome (PRES) such as focal regions of symmetric edema affecting the white mater of the parietal and occipital lobes [15]. CSA-related neurotoxicity usually resolves completely with dose reduction or drug withdrawal, but this can have major implications on clinical outcomes, particularly in the face of ongoing GvHD. Furthermore, some CSA-related neurological lesions are irreversible and associated with the later occurrence of epilepsy and persistent abnormalities in the electroencephalogram (EEG) [16]. However, little information is available regarding CSA-related neurotoxicity in children undergoing HID-HSCT.

In this study, we retrospectively examined the data of children who underwent HID-HSCT in order to describe the risk factors and long-term outcomes of CSA-related neurotoxicity. Our aim was to identify factors that potentially could be targeted to prevent post-transplantation CSA-related neurotoxicity or facilitate its early diagnosis and thereby improve survival outcomes and quality of life for patients following HID-HSCT.

\section{Methods}

\section{Study design and patients}

This retrospective case series study included pediatric patients treated with HID-HSCT at the Department of Hematology, Fujian Medical University Union Hospital, Fuzhou, Fujian, China between February 2013 and January 2017. The inclusion criteria were: 1 ) age $\leq 18$ years; 2) received HID-HSCT from a family member who shared one HLA haplotype with the recipient (but differed to varying degrees with regard to the HLA-A, $-\mathrm{B}$ and -DR antigens of the unshared HLA haplotype); and 3) received CSA as prophylaxis against GvHD. Patients with neurological disorders before HID-HSCT, including cerebral hemorrhage and central nervous system leukemia, were excluded. The Ethics Committee of Fujian Medical University Union Hospital approved the study (No. 2020ky043) and waived the requirement for informed consent because the analysis was retrospective.

\section{CSA administration}

The FA5-BUCY conditioning regimen and GvHD prophylaxis were administered as described previously by Yang et al. [17]. Briefly, all 51 patients underwent aplasiainducing salvage therapy consisting of $30 \mathrm{mg} / \mathrm{m}^{2} /$ day fludarabine and $2 \mathrm{~g} / \mathrm{m}^{2} /$ day Ara-C (cytarabine) for 5 consecutive days from day -13 to day -9 , followed after 1 day of rest by $3.2 \mathrm{mg} / \mathrm{kg} /$ day BU from day -7 to day -5 and $1.8 \mathrm{~g} / \mathrm{m}^{2} /$ day $\mathrm{CY}$ from day -4 to day -3 . GvHD prophylaxis consisted of rabbit anti-thymocyte globulin (Thymoglobulin [Genzyme] at $10 \mathrm{mg} / \mathrm{kg}, 20$ patients; ATG-Fresenius ${ }^{\circ}$ at $40 \mathrm{mg} / \mathrm{kg}, 23$ patients) from day -4 to day-1, CSA (plasma levels of 100-250 ng/ml; starting from day -10 intravenously at $1.5 \mathrm{mg} / \mathrm{kg}$ every $12 \mathrm{~h}$, followed by oral administration at $5-6 \mathrm{mg} / \mathrm{kg} /$ day after completion of the transplantation, and tapering from the second or third month if no signs of GvHD were present), mycophenolate mofetil $(5 \mathrm{mg} / \mathrm{kg}$ bid, starting from day +7 and tapered after engraftment), and short-term methotrexate (MTX, $15 \mathrm{mg} / \mathrm{m}^{2}$ at day +1 , and $10 \mathrm{mg} / \mathrm{m}^{2}$ at day +3 and +6 ). All patients received methylprednisolone for preventing serum sickness associated ATG at $0.8 \mathrm{mg} / \mathrm{kg} /$ day from day -4 to granulocyte implantation. All stem cells were derived from the bone marrow or peripheral blood of the patients' fathers.

\section{Monitoring for adverse effects}

Monitoring for CSA-related adverse effects consisted of physical examination, blood pressure measurements and routine blood biochemistry tests (including magnesium level), which were performed daily up to day 30 and then 3 times weekly up to day 60. Hypertension was defined according to the 2010 Chinese guidelines for the management of hypertension in children and adolescents (blood pressure above the 75th percentile for age and weight) [18] and was treated with oral calcium channel antagonists. Fluid overload was considered if hypertension or neurological symptoms developed and was treated with intravenous furosemide. Magnesium supplementation was given if plasma magnesium levels fell below $0.8 \mathrm{mmol} / \mathrm{L}$.

Since there are no definitive criteria for CSA-related neurotoxicity, this adverse effect was diagnosed clinically using similar guidelines to those described in previous reports $[13,14,19]$. The diagnosis of CSA-related neurotoxicity was based on the appearance of neurological manifestations during CSA administration (including altered consciousness, seizures, tremors and continuous headache) and the exclusion of other conceivable causes (such as infection, cerebral hemorrhage, metabolic abnormalities, central nervous system leukemia and 
electrolyte disturbances). If CSA-related neurotoxicity was suspected, CSA was immediately discontinued, and the patient was examined using computed tomography (CT), MRI and electroencephalography. Furthermore, the amelioration of neurological symptoms after the withdrawal of CSA was taken as further evidence in support of a diagnosis of CSA-related neurotoxicity. MRI was performed to exclude other diagnoses and to look for radiological manifestations of PRES (which would support the diagnosis of CSA-related neurotoxicity). In cases with manifestations of epilepsy, electroencephalography was repeated after $24 \mathrm{~h}$ and again at 1 month following control of the acute symptoms with anticonvulsants. Electroencephalography was then performed every 3 months for 1 year and annually thereafter if there was no recurrence of seizures or every 3-6 months if recurrence occurred.

\section{Statistical analysis}

For the analysis, the patients were divided into two groups (neurotoxicity group and non-neurotoxicity group) based on whether CSA-related neurotoxicity occurred. Categorical variables are presented as $n(\%)$ and were compared between groups using Fisher's exact test or the chi-squared test. Continuous variables were tested for normality, and all the datasets were found not to be normally distributed. Therefore, continuous variables are expressed as median (range) and were compared between groups using the Mann-Whitney U test. Deaths and relapses were considered as competing events, and treatment-related mortality (TRM) was determined using Kaplan-Meier analysis by the log-rank method. The null hypothesis was rejected for $P$-values $<0.05$. Statistical analyses were performed using SPSS version 21 (IBM, Armonk, NY, USA).

\section{Results}

\section{Clinical characteristics of the patients included in the analysis}

A total of 51 pediatric patients (39 males, 76.5\%) with a median age of 8 (range 1.1-18) years were included in this study. The clinical characteristics of these $51 \mathrm{pa}-$ tients are summarized in Table 1.

\section{Clinical characteristics of the patients diagnosed with CSA-related neurotoxicity}

Eleven of the 51 children (21.5\%) who received HIDHSCT during the study period developed seizure disorders or encephalopathy, but 4 of these 11 children was excluded of CSA-related neurotoxicity due to obvious alternative causes (cerebral hemorrhage in 2 patients, CNS infection in 1 patient and metabolic encephalopathy in 1 patient). Therefore, 7 patients (13.7\%) were diagnosed with CSA-related neurotoxicity (neurotoxicity group).
The 7 children with CSA-related neurotoxicity included 5 boys and 2 girls with a median age of 7 (range, 4-9) years. The median time to neutrophil and thrombocyte engraftment was 11 (range, 10-19) days and 12 (range, 10-22) days, respectively. The clinical characteristics of the 7 patients with CSA-related neurotoxicity are summarized in Table 2.

The median number of days from HID-HSCT to neurotoxicity was 38 (range, -3 to 161) days. The diagnosis of CSA-related neurotoxicity was made during the conditioning stage in 1 patient, at $0-100$ days after transplantation in 4 patients, and after day 100 in 2 patients. During CSA dose adjustment, the trough plasma level of CSA ranged from $107.8 \mathrm{ng} / \mathrm{mL}$ to $584 \mathrm{ng} / \mathrm{mL}$ (the CSA dose was reduced whenever the level exceeded $250 \mathrm{ng} / \mathrm{mL}$ ). All 7 patients who developed neurotoxicity presented with prodromes 1-2 days before overt neurotoxicity, and the prodromes included hypertension $(n=5)$, transient headache $(n=3)$, vomiting $(n=2)$, fatigue $(n=2)$, dysphoria $(n=2)$ and visual hallucinations $(n=1)$. At the time of overt neurotoxicity, 5 cases were complicated with GvHD, 5 cases with infection, 3 cases with hemorrhagic cystitis, and 5 cases with hypertension. CSA-related neurotoxicity manifested as generalized seizures $(n=7)$, persistent headache $(n=3)$, tremors $(n=2)$, visual disturbance $(n=2)$, psychosis $(n=1)$, aphasia $(n=1)$ and dysphagia $(n=1)$. Plasma levels of CSA were within the desired range in all patients (median, $82.1 \mathrm{ng} / \mathrm{mL}$; range, $57.7-118.3 \mathrm{ng} / \mathrm{mL}$ ) at the time that neurological symptoms appeared. CSF examinations were performed in 5 patients and returned normal findings in all cases.

\section{Neuroimaging and electroencephalography}

Neuroimaging and electroencephalography were performed in all patients with CSA-related neurotoxicity. Emergency CT scanning was carried out within $24 \mathrm{~h}$ of the appearance of neurological symptoms to exclude intracranial hemorrhage. In patient \#4, CT demonstrated a minimal subdural hemorrhagic layer compatible with post-epileptic trauma. MRI was performed within 3 days of the appearance of neurological symptoms after the patient's vital signs had stabilized (our hospital did not have access to emergency MRI). In 6 of the 7 patients, MRI showed asymmetric involvement of the posterior portions of the cerebral hemispheres, and hyperintense signals were evident on apparent diffusion coefficient (ADC) maps that were consistent with vasogenic edema (Fig. 1a). In the remaining case (patient \#6), MRI demonstrated an atypical abnormality that manifested as hyperintense signals in the thalamus and hippocampus predominantly involving the white matter but also the cortex (Fig. 1b). Patient \#4 had a complicated cerebral hemorrhage that was associated with PRES (Fig. 1 c). Follow-up MRI examinations were obtained over a 
Table 1 Clinical characteristics of the 51 children who underwent haploidentical hematopoietic stem cell transplantation

\begin{tabular}{ll}
\hline Characteristic & Value \\
\hline Age at HID-HSCT (years), median (range) & $8(1.1-18)$ \\
Gender, $n$ (\%) & \\
Female & $12(23.5 \%)$ \\
Male & $39(76.5 \%)$ \\
Primary disease, $n$ (\%) & \\
Acute lymphoblastic leukemia & $14(27.4 \%)$ \\
Acute myeloid leukemia & $25(49.0 \%)$ \\
Myelodysplastic syndrome-secondary acute & $4(7.9 \%)$ \\
myeloid leukemia & \\
Advanced myelodysplastic syndrome & $2(3.9 \%)$ \\
Acquired severe aplastic anemia & $6(11.8 \%)$ \\
a Remission status, $n$ (\%) & \\
First complete remission (CR1) & $24(55.8 \%)$ \\
Second complete remission (CR2) & $5(11.6 \%)$ \\
Not in remission & $14(32.6 \%)$ \\
Relationship of donor to recipient, $n$ (\%) & \\
Parent & \\
Sibling & \\
(range) & \\
Follow-up time (days), median (range) \\
and recipient, $n$ (\%) \\
Matched \\
Mismatched
\end{tabular}

${ }^{\mathrm{a}}$ Remission status is for 43 children with acute leukemia. HID-HSCT, haploidentical hematopoietic stem cell transplantation

period of 2-4 months after the first MRI scan in the 6 children who survived despite developing CSA-related neurotoxicity. Four of these 6 patients exhibited complete resolution of the MRI abnormalities at a median of 2 months (range, 2-8 months) after CSA withdrawal, while 2 cases (patients \#2 and \#3) had MRI abnormalities that persisted over 3 years (Fig. 1d and e).

It was possible to record an EEG at the time of neurological symptom onset in 6 of the 7 children. The main
EEG abnormalities included high-voltage slow-waves $(n=5)$, sharp waves $(n=4)$, spikes $(n=3)$ and spikewave complexes $(n=3)$. The EEG demonstrated status epilepticus in 3 of the 6 patients and focal delta activity and focal epileptiform discharges in the other 3 patients. Non-epileptiform EEG abnormalities were still detectable in 5 patients ( $\# 1, \# 4, \# 5, \# 6$ and $\# 7$ ) during the $2-8$ week period after the onset of symptoms. Long-term follow-up electroencephalography examinations were performed in 2 cases (patients \#2 and \#3) with persistent neurological symptoms; the resolution of their EEG abnormalities correlated with their clinical improvement.

\section{Management of CSA-related neurotoxicity}

The treatments administered to the 7 patients with CSA-related neurotoxicity are summarized in Table 3. CSA was withdrawn immediately following the occurrence of neurotoxicity. Tacrolimus alone $(n=2)$ or with mycophenolate mofetil $(n=5)$ was initiated 2 days after CSA washout, with monitoring of the plasma levels. Seizures were treated immediately with intravenous diazepam, and this was followed by anticonvulsive therapy with midazolam. Patients \#3 and \#4 also required sodium valproate injections to control status epilepticus. Anticonvulsive therapy was tapered and stopped after normalization of the EEG. However, patients \#2 and \#3 subsequently required anti-epileptic drugs and trihexyphenidyl due to the development of secondary epilepsy (focal epileptiform activity) and tremors. Patient \#4 was given anti-psychotic drugs due to the development of psychosis. Additionally, intravenous mannitol was used in 4 patients to treat cerebral edema secondary to seizure recurrence and confusion, vomiting, headache and blurred vision related to intracranial hypertension. Furosemide and captopril were used to control blood pressure and maintain water, electrolyte and acid-base balance. Other forms of supportive care were also provided as necessary.

\section{Outcomes}

Death occurred in 1 of the 7 patients with CSA-related neurotoxicity (patient \#6), who developed grade IV GvHD and disseminated intravascular coagulation at 5 months post-HSCT and subsequently died from hemorrhagic shock and respiratory failure on day +160 without neurological symptoms. The remaining $6 \mathrm{pa}-$ tients were alive at the last follow-up. Three of these 6 patients had neurological sequelae, including secondary epilepsy (patients \#2 and \#3) and psychosis (patient \#4). The 2 patients with secondary epilepsy were administered oxcarbazepine, which was successfully withdrawn in patient \#2 after 3 years. However, patient \#3 required continuous treatment with the anti-epileptic agent because drug withdrawal for 3-6 months resulted in EEG 
Table 2 Clinical characteristics of the 7 patients diagnosed with cyclosporine A-related neurotoxicity

\begin{tabular}{|c|c|c|c|c|c|c|c|}
\hline Patient number & $\# 1$ & $\# 2$ & $\# 3$ & $\# 4$ & $\# 5$ & $\# 6$ & $\# 7$ \\
\hline Gender & M & $\mathrm{F}$ & M & M & $\mathrm{F}$ & M & M \\
\hline Age at HID-HSCT (years) & 8 & 7 & 7 & 9 & 8 & 7 & 4 \\
\hline Underlying disease & MDS & ALL & AML & MDS-SAML & AML & AML & ALL \\
\hline Remission status & NR & CR1 & CR1 & CR1 & CR1 & CR1 & PR \\
\hline HLA typing & $6 / 10$ & $5 / 10$ & $7 / 10$ & $5 / 10$ & $5 / 10$ & $5 / 10$ & $5 / 10$ \\
\hline Donor-recipient gender & $\mathrm{F}-\mathrm{M}$ & $F-F$ & $\mathrm{~F}-\mathrm{M}$ & F-M & $M-F$ & M-M & M-M \\
\hline ABO type of donor and recipient & Matched & Mismatched & Mismatched & Mismatched & Matched & Mismatched & Matched \\
\hline Mononuclear cells $\left(\times 10^{8} / \mathrm{kg}\right)$ & 6.14 & 13.1 & 17.5 & 17.45 & 5.6 & 1.82 & 16.37 \\
\hline CD34+ cells $\left(\times 10^{6} / \mathrm{kg}\right)$ & 2.3 & 2.5 & 6.85 & 3.17 & 8.81 & 10.14 & 5.33 \\
\hline Neutrophil engraftment time (days) & 11 & 10 & 11 & 19 & 12 & 16 & 10 \\
\hline Thrombocyte engraftment time (days) & 15 & 10 & 11 & 22 & 12 & 17 & 10 \\
\hline
\end{tabular}

ALL Acute lymphoblastic leukemia, AML Acute myeloid leukemia, CR Complete remission, F Female, HID-HSCT Haploidentical hematopoietic stem cell transplantation, $M$ Male, MDS-SAML Myelodysplastic syndrome-secondary acute myeloid leukemia, NR No response, $P R$ Partial remission

abnormalities and seizure recurrence characterized by sensory disturbances. Patient \#4 was given risperidone as an anti-psychotic agent and did not have symptom recurrence. Five patients were alive and symptom-free at a median follow-up of 61.9 (range, 31.9-67.4) months after HSCT (Table 3).

\section{Risk factors and prognosis}

Univariate analysis revealed that the incidence of hypertension during treatment with CSA was significantly higher in the neurotoxicity group than in the nonneurotoxicity group $(71 \%$ vs. $11 \%, P=0.002$; Table 4$)$. However, there were no significant differences between groups with regard to age at HSCT, gender, underlying diseases, electrolyte imbalance, maximum CSA level, $\mathrm{ABO}$ blood type matching between donor and recipient, or gender matching between donor and recipient (Table 4). Treatment-related mortality (TRM) rates were 87.71 and $85.15 \%$ in the neurotoxicity $(n=7)$ and nonneurotoxicity $(n=44)$ groups, respectively, with no significant difference between the two groups $(P=0.93)$, as shown in Fig. 2.

\section{Discussion}

A notable finding of this study was that $13.7 \%$ of children who underwent HID-HSCT for hematopathy developed CSA-related neurotoxicity after a median 38 days. Furthermore, 6 of the 7 patients with CSA-related neurotoxicity had MRI features consistent with PRES, although 1 patient exhibited atypical abnormalities. Hypertension was the most common prodrome, occurring in $71 \%$ of those who developed CSA-related neurotoxicity. Importantly, hypertension during prophylaxis with CSA was more common in patients with CSArelated neurotoxicity than in those without neurotoxicity (71\% vs. $11 \%)$. Our findings indicate that CSA-related neurotoxicity is not uncommon in children with hematopathy undergoing HID-HSCT. Furthermore, blood pressure should be carefully evaluated during the early post-transplantation period, since hypertension was the most common prodrome and the only factor in our analysis that differed significantly between patients with CSA-related neurotoxicity and those without.

In this case series, the incidence of CSA-related neurotoxicity was $13.7 \%$ in children with hematological malignancies or aplastic anemia treated with HID-HSCT. This incidence was higher than $4.7 \%$ reported by a previous Italian multi-center retrospective study [20]. This might be based on the following reasons. On the one hand, the patients in the Italian study mostly had nonmalignant hematological diseases, and previous studies have suggested that the incidence of CSA-related neurotoxicity after HSCT is higher in patients with malignant disorders (9-28.8\%) compared with those with nonmalignant disorders $(4-11 \%)[14,21]$. On the other hand, transplantation was mostly HLA-matched allo-HSCT and autologous HSCT in Zama et al. [20], while HLAunmatched HSCT is considered a risk factor for PRES [22]. In addition, the incidence of CSA-related neurotoxicity may be associated with donor type. For example, Faraci et al. reported that the rate of neurological complications varied with the source of stem cells $(27.1 \%$ for cells from unrelated donors, $13.9 \%$ for cells from related donors, and $2.3 \%$ for autologous cells) [11]. Similarly, Koh et al. described neurotoxicity rates of $18.0 \%$ for unrelated donors, $11.1 \%$ for mismatched related donors and $3.3 \%$ for matched related donors [10]. Moreover, Elgarten et al. reported no cases of calcineurin inhibitorrelated neurotoxicity in pediatric patients with malignant and nonmalignant diseases who underwent HSCT with matched sibling donors [23]. Since Zimmer et al. also found that the frequency of CSA-related neurotoxicity 
a

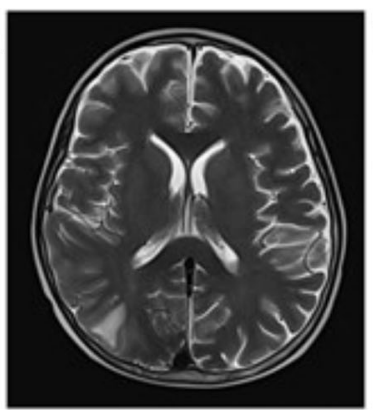

d

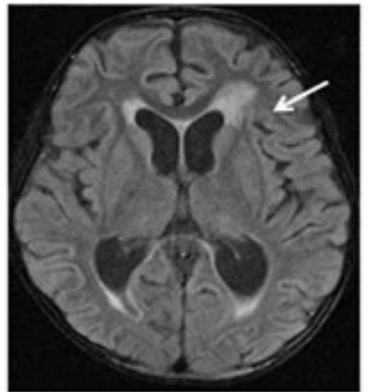

g

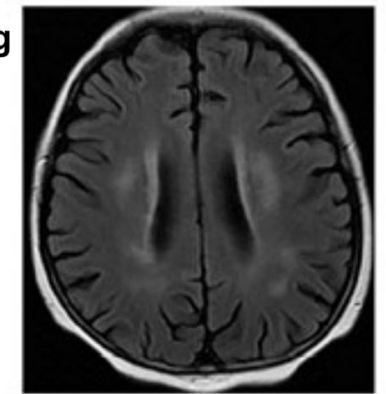

b

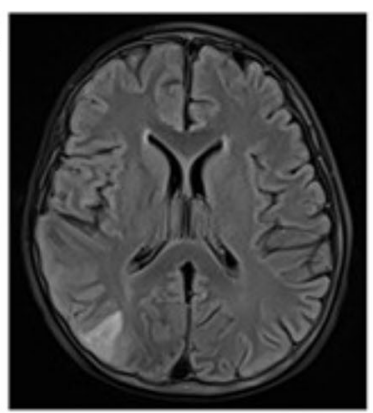

e

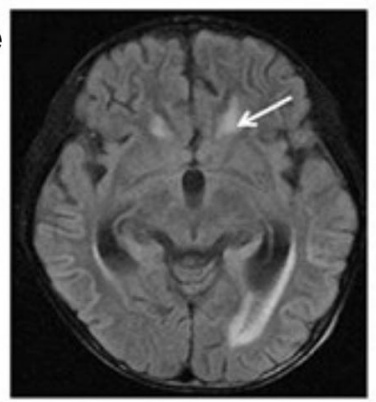

h

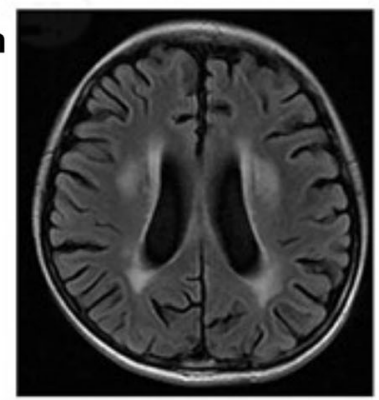

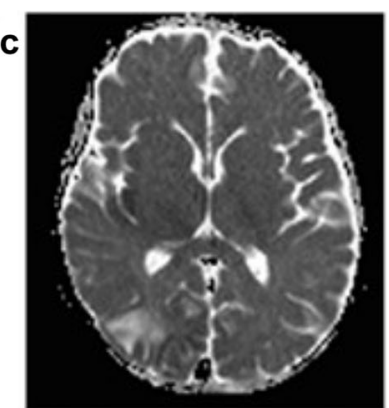
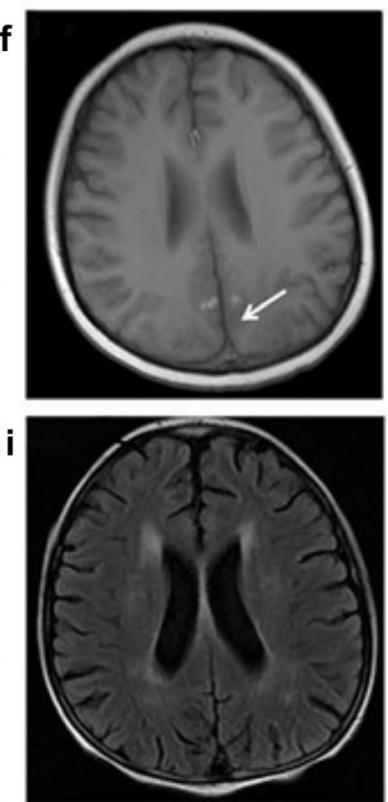

k
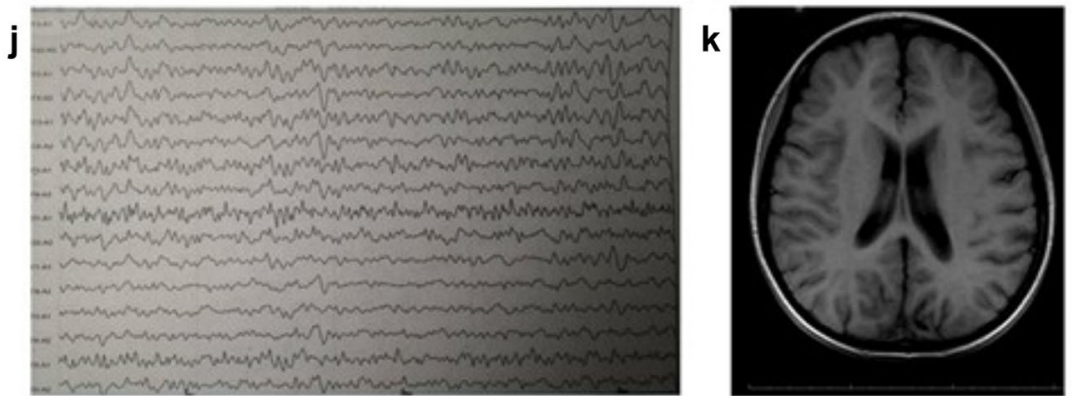

Fig. 1 Brain magnetic resonance imaging (MRI) and electroencephalography. $\mathbf{a}, \mathbf{b}, \mathbf{c}$ MRI of the brain of patient \#1 showing asymmetrical involvement of the cortex and subcortical white matter with high-intensity signals evident on axial T2-weighted. a T2-fluid attenuation inversion recovery (T2-FLAIR). $\mathbf{b}$ Apparent diffusion coefficient (ADC). c Scans. Similar MRI findings were obtained in five other patients with cyclosporine A-related neurotoxicity (patients $\# 2, \# 3, \# 4, \# 5$ and \#7). $\mathbf{d}$ and $\mathbf{e}$. Axial FLAIR MRI of the brain of patient \#6 (obtained 3 days after the onset of symptoms) showing hyperintense signals in the periventricular white matter (white arrow in $\mathbf{d}$ and $\mathbf{e}$ ) as well as the thalamus (blue arrow in $\mathbf{d}$ ) and hippocampus (blue arrow in e). $\mathbf{f}$ Axial T1weighted MRI of the brain of patient \#4 obtained 3 days after the onset of symptoms. This patient had cerebral hemorrhage associated with posterior reversible encephalopathy syndrome that manifested as a parenchymal hematoma and small hemorrhages $<5 \mathrm{~mm}$ in size. The white arrow indicates a microbleed in the occipital lobe. $\mathbf{g}, \mathbf{h}$ and $\mathbf{i}$. Follow-up MRI of the brain of patient \#2. $\mathbf{g}$ Patchy shadows with high signal intensity were observed in the lateral periventricular white matter 3 days after the onset of symptoms. $\mathbf{h}$ Hyperintense patchy shadowing in the lateral periventricular white matter was increased at 1 month after onset, despite an improvement in clinical symptoms at this time. i Patchy shadowing was less evident at 6 months after symptom onset. $\mathbf{j}$ and $\mathbf{k}$. Electroencephalography and MRI findings in patient \#3. MRI showed local cortical atrophy in the left parietal and occipital lobes, and the electroencephalogram demonstrated a spike rhythm originating from the same region of the brain 
Table 3 Clinical and treatment-related data for the 7 patients with cyclosporine A-related neurotoxicity

\begin{tabular}{|c|c|c|c|c|c|c|c|}
\hline Patient number & $\# 1$ & $\# 2$ & $\# 3$ & $\# 4$ & $\# 5$ & $\# 6$ & $\# 7$ \\
\hline Day of onset post-HSCT & +38 & +161 & +24 & -3 & +1 & +46 & +137 \\
\hline Prodromes & $\begin{array}{l}\text { Transient } \\
\text { headache, } \\
\text { hypertension }\end{array}$ & $\begin{array}{l}\text { Vomiting, transient } \\
\text { headache, } \\
\text { hypertension }\end{array}$ & $\begin{array}{l}\text { Dysphoria, } \\
\text { hypertension }\end{array}$ & $\begin{array}{l}\text { Fatigue, } \\
\text { hypertension, } \\
\text { visual } \\
\text { hallucination }\end{array}$ & $\begin{array}{l}\text { Transient } \\
\text { headache, } \\
\text { vomiting }\end{array}$ & $\begin{array}{l}\text { Dysphoria, } \\
\text { hypertension }\end{array}$ & Fatigue \\
\hline Acute symptoms & $\begin{array}{l}\text { Persistent } \\
\text { headache, } \\
\text { seizures }\end{array}$ & $\begin{array}{l}\text { Status epilepticus, } \\
\text { tremors, dysphagia, } \\
\text { persistent headache }\end{array}$ & $\begin{array}{l}\text { Status epilepticus, } \\
\text { aphasia, tremors }\end{array}$ & $\begin{array}{l}\text { Status } \\
\text { epilepticus, } \\
\text { visual } \\
\text { disturbance, } \\
\text { psychosis }\end{array}$ & $\begin{array}{l}\text { Seizures, visual } \\
\text { disturbance, } \\
\text { persistent } \\
\text { headache }\end{array}$ & $\begin{array}{l}\text { Status } \\
\text { epilepticus }\end{array}$ & Seizures \\
\hline $\begin{array}{l}\text { CSA level at time of } \\
\text { neurotoxicity }(\mathrm{ng} / \mathrm{mL})\end{array}$ & 118.3 & 110 & 89.4 & 68.3 & 57.7 & 67.2 & 82.1 \\
\hline $\begin{array}{l}\text { Maximum trough CSA } \\
\text { level before CSA-related } \\
\text { neurotoxicity }(\mathrm{ng} / \mathrm{mL})\end{array}$ & 307 & 500 & 135 & 211 & 107.8 & 118 & 584 \\
\hline $\begin{array}{l}\text { Most severe GVHD } \\
\text { grade before CSA- } \\
\text { related neurotoxicity }\end{array}$ & $\begin{array}{l}\text { Grade II, skin } \\
\text { and gut }\end{array}$ & $\begin{array}{l}\text { Grade III, skin and } \\
\text { gut }\end{array}$ & Grade II, skin & No GvHD & No GvHD & Grade III, gut & $\begin{array}{l}\text { Grade IV, } \\
\text { gut }\end{array}$ \\
\hline $\begin{array}{l}\text { Immune suppression } \\
\text { after CSA-related } \\
\text { neurotoxicity }\end{array}$ & $\begin{array}{l}\text { Tacrolimus, } \\
\text { MMF, CS, } \\
\text { basiliximab }\end{array}$ & $\begin{array}{l}\text { Tacrolimus, MMF, } \\
\text { CS, basiliximab }\end{array}$ & $\begin{array}{l}\text { Tacrolimus, MMF, } \\
\text { CS, basiliximab }\end{array}$ & $\begin{array}{l}\text { Tacrolimus, } \\
\text { MMF }\end{array}$ & Tacrolimus & $\begin{array}{l}\text { Tacrolimus, } \\
\text { CS }\end{array}$ & $\begin{array}{l}\text { Tacrolimus, } \\
\text { MMF, CS, } \\
\text { basiliximab }\end{array}$ \\
\hline $\begin{array}{l}\text { Acute treatment for } \\
\text { neurological symptoms }\end{array}$ & $\begin{array}{l}\text { Diazepam, } \\
\text { midazolam, }\end{array}$ & $\begin{array}{l}\text { Diazepam, } \\
\text { midazolam, } \\
\text { trihexyphenidyl }\end{array}$ & $\begin{array}{l}\text { Diazepam, } \\
\text { midazolam, sodium } \\
\text { valproate, } \\
\text { trihexyphenidyl }\end{array}$ & $\begin{array}{l}\text { Diazepam, } \\
\text { midazolam, } \\
\text { sodium } \\
\text { valproate }\end{array}$ & $\begin{array}{l}\text { Diazepam, } \\
\text { midazolam }\end{array}$ & $\begin{array}{l}\text { Diazepam, } \\
\text { midazolam }\end{array}$ & $\begin{array}{l}\text { Diazepam, } \\
\text { midazolam }\end{array}$ \\
\hline Neurological sequelae & None & Secondary epilepsy & Secondary epilepsy & Psychosis & None & - & None \\
\hline $\begin{array}{l}\text { Chronic treatment/ } \\
\text { duration }\end{array}$ & Nil & $\begin{array}{l}\text { Oxcarbazepine/3 } \\
\text { years }\end{array}$ & $\begin{array}{l}\text { Oxcarbazepine/ } \\
\text { continuous }\end{array}$ & $\begin{array}{l}\text { Risperidone/2 } \\
\text { years }\end{array}$ & None & - & None \\
\hline $\begin{array}{l}\text { Outcome/'last follow-up } \\
\text { (days post-HSCT) }\end{array}$ & Alive/+ 2023 & Alive/+ 1909 & Alive/+ 1818 & Alive /+ 1899 & Alive/+ 1798 & Dead/+ 160 & Alive/+ 958 \\
\hline $\begin{array}{l}\text { Cause of death/current } \\
\text { complications }\end{array}$ & $\begin{array}{l}\text { Symptom- } \\
\text { free }\end{array}$ & Symptom-free & Secondary epilepsy & Symptom-free & Symptom-free & $\begin{array}{l}\text { Grade IV } \\
\text { GvHD }\end{array}$ & $\begin{array}{l}\text { Symptom- } \\
\text { free }\end{array}$ \\
\hline
\end{tabular}

CS Corticosteroids, CSA Cyclosporine A, GvHD Graft-versus-host disease, HSCT Hematopoietic stem cell transplantation, MMF Mycophenolate mofetil. ${ }^{2}$ As of 15 November 2018, except for patient \#6 for whom the last follow-up was 29 May 2016

increased with greater HLA disparity between donor and recipient [24], it is likely that our rate of $13.7 \%$ would be higher than that for children who receive HSCT from HLA-matched siblings.

Several factors may be associated with a higher incidence of CSA-related neurotoxicity in pediatric patients who undergo HID-HSCT. First, patients with GvHD above grade II may be at an increased risk of neurotoxicity [25]. Second, CSA-related neurotoxicity is more likely to occur in patients undergoing HSCT from unrelated or unmatched donors [26], which in part may be due to differences in GvHD incidence and severity. Third, the use of intravenous busulfan in the preparative regimen can induce seizures, and this may play a role in the subsequent appearance of CSA-related neurotoxicity [14]. Fourth, younger children ( $<6$ years of age) tend to suffer more severe seizures in the acute stage than older patients and are relatively more likely to develop epilepsy and neurotoxicity disorders in the future [19]. The vertebrobasilar circulation in children has reduced adrenergic innervation [27], and is less tolerant to changes in arterial blood pressure [28]. Therefore, young children may be particularly susceptible to CSA-related neurotoxicity. Fifth, there is evidence that hypertension may be associated with CSA-related neurotoxicity. For example, hypertension has been reported as a prodrome to CSA-related neurotoxicity in 83\% [14] and 46\% [29] of patients, which is broadly comparable to our finding that $71 \%$ of patients exhibited hypertension as a prodrome. Furthermore, hypertension after CSA treatment was the only factor in our analysis associated with an increased risk of CSA-related neurotoxicity.

Neuroimaging now plays a central role in the diagnosis and long-term follow-up of CSA-related neurotoxicity. CT is typically the first tool used to investigate patients with acute neurological disorders, but this imaging technique identifies lesions in only about $50 \%$ of PRES cases [30]. Since children receiving transplants can present with a wide spectrum of acute neurologic complications, MRI-based evaluation is essential for the accurate 
Table 4 Comparison of clinical characteristics between patients with cyclosporine A-related neurotoxicity and those without

\begin{tabular}{|c|c|c|c|}
\hline Characteristic & Neurotoxicity & Non-neurotoxicity & $P$ \\
\hline No. of patients & 7 & 44 & \\
\hline Male gender, $n(\%)$ & $5(72 \%)$ & $34(78 \%)$ & 0.662 \\
\hline Age at HID-HSCT (years), median (range) & $7(1.6)$ & $8(4.4)$ & 0.212 \\
\hline Underlying disease, $n$ (\%) & & & 0.221 \\
\hline Acute leukemia & $6(86 \%)$ & $38(87 \%)$ & \\
\hline Myelodysplastic syndrome & $1(14 \%)$ & $1(2 \%)$ & \\
\hline Aplastic anemia & $0(0 \%)$ & $5(11 \%)$ & \\
\hline State of underlying disease at HSCT, n (\%) & & & 0.685 \\
\hline Complete remission & $5(72 \%)$ & $25(57 \%)$ & \\
\hline Not in remission & $2(28 \%)$ & $19(43 \%)$ & \\
\hline Hypertension after CSA, $n$ (\%) & $5(71 \%)$ & $5(11 \%)$ & 0.002 \\
\hline \multicolumn{4}{|l|}{ Electrolyte imbalance, $n(\%)$} \\
\hline Hyponatremia & $3(43 \%)$ & $7(16 \%)$ & 0.095 \\
\hline Hypokalemia & $6(86 \%)$ & $33(75 \%)$ & 0.223 \\
\hline Hypocalcemia & $5(71 \%)$ & $18(41 \%)$ & 0.221 \\
\hline Hypomagnesemia & $2(29 \%)$ & $10(23 \%)$ & 0.662 \\
\hline Maximum trough CSA level > 250 ng/mL, n (\%) & $3(43 \%)$ & $12(27 \%)$ & 0.406 \\
\hline ABO blood type of donor and recipient, $n(\%)$ & & & 0.427 \\
\hline Matched & $3(43 \%)$ & $27(61 \%)$ & \\
\hline Mismatched & $4(57 \%)$ & 17 (39\%) & \\
\hline Gender of donor and recipient, $n(\%)$ & & & 0.923 \\
\hline Matched & $3(43 \%)$ & $18(41 \%)$ & \\
\hline Mismatched & $4(57 \%)$ & $26(59 \%)$ & \\
\hline Acute GvHD, $n(\%)$ & & & 0.300 \\
\hline Yes & $5(72 \%)$ & $38(86 \%)$ & \\
\hline No & $2(28 \%)$ & $6(14 \%)$ & \\
\hline
\end{tabular}

CSA Cyclosporine A, HID-HSCT Haploidentical hematopoietic stem cell transplantation, SD Standard deviation, GvHD Graft-versus-host disease

diagnosis of PRES. DWI and ADC maps can help to distinguish vasogenic edema from cytotoxic edema [31]. Vasogenic edema typically presents as hyperintensity on $\mathrm{ADC}$ and isointensity or hypointensity on DWI, while cytotoxic edema usually manifests as hypointensity on

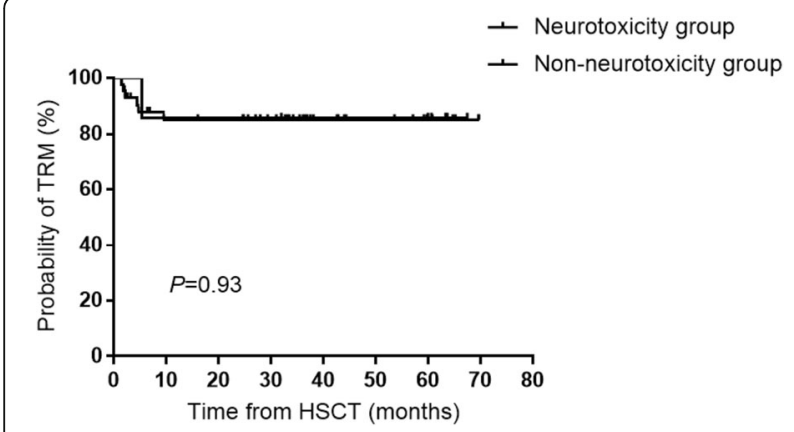

Fig. 2 Kaplan-Meier analysis of treatment-related mortality (TRM) in the neurotoxicity and non-neurotoxicity groups. TRM rates were 87.71 and $85.15 \%$ in the neurotoxicity $(n=7)$ and non-neurotoxicity ( $n=44)$ groups, respectively, with no significant difference between the two groups $(P=0.93)$
ADC and hyperintensity on DWI [32]. Although CSArelated neurotoxic events are typically thought to be confined to fluid extravasation, more severe endothelial damage has been reported, including erythrocyte extravasation with parenchymal hemorrhage [33]. Cerebral hemorrhage is associated with PRES in $5-19 \%$ of cases [34], which might explain the focal hemorrhages observed in the MRI scans of patient \#4 in our study.

The clinical and imaging manifestations of PRES are reversible in the majority of patients $(70 \%)$ provided CSA is promptly reduced in dosage or withdrawn, but a delay in the diagnosis and treatment of PRES can result in irreversible neurological damage [33]. Karia et al. reported a strong association between MRI severity and clinical outcome [35]. Furthermore, children with persistent EEG or 
imaging abnormalities have been reported to be at higher risk of seizure recurrence following CSA-related neurotoxicity [36]. Cerebral hyperperfusion due to hypertension and aggravation of vascular endothelial injury may be important mechanisms by which CSA increases the permeability of the blood-brain barrier [37]. Irrespective of the underlying pathology, MRI and electroencephalography can be extremely useful for the detection of lesions due to CSA-related neurotoxicity and the long-term follow-up of patients with persistent abnormalities. In the present study, three patients with persistent EEG or imaging abnormalities had neurological sequelae. However, two patients subsequently recovered, and the symptoms in the other patient were controlled after standardized treatment.

In the case of severe hypertension during the acute phase of neurotoxicity, arterial blood pressure should be reduced by $\sim 25 \%$ within the first hour (after the exclusion of cerebral infarction) and then more slowly [38]. CSA should be discontinued following the occurrence of neurotoxicity, and tacrolimus is the most commonly used alternative agent in the event of CSA-related neurotoxicity [13, 34, 39]. Although tacrolimus is also associated with neurotoxicity $[13,39]$, it did not produce neurological adverse effects in this series of patients. Anti-convulsive therapy should be administered as early as possible to control ongoing seizures. Prolonged prophylactic treatment with anti-epileptic drugs is unnecessary in patients with occasional or provoked seizures due to CSA-related neurotoxicity, but such drugs should be considered in cases with later development of secondary epilepsy [34]. In the present study, 1 of the 7 patients with CSA-related neurotoxicity (14\%) required long-term anti-convulsive therapy.

The 5-year OS rate for the pediatric patients who developed CSA-related neurotoxicity after HID-HSCT was not significantly different to that for the patients who did not exhibit neurotoxicity. This is a promising finding, as it suggests that appropriate detection and intervention can ameliorate the long-term consequences of these relatively common adverse events.

This study has some limitations. First, this was a retrospective analysis, so the results are prone to information bias and selection bias. In addition, the rate of hypertension could be underestimated in control patients. Second, this was a single-center study, so the generalizability of the findings is not known. Third, the sample size was small, so the study may have been underpowered to detect some real differences between groups. Fourth, unknown confounding factors may have influenced the analysis. Fifth, CSA-related neurotoxicity was diagnosed on the basis of clinical and radiological findings, but it is possible that some mild cases may have been missed, leading to an underestimation of the incidence.

\section{Conclusion}

There is a relatively high incidence of CSA-related neurotoxicity in children with hematological disorders undergoing HID-HSCT. Awareness of the clinical features of CSA-related neurotoxicity (particularly hypertension) can facilitate rapid diagnosis and timely implementation of appropriate interventions. Moreover, patients with persistent EEG or imaging abnormalities can benefit from MRI and EEG examinations as part of their long-term follow-up program.

\section{Abbreviations}

ADC: Apparent diffusion coefficient; CSA: Cyclosporine A; CT: Computed tomography; DWl: Diffusion weighted imaging; GvHD: Graft-versus-host disease; EEG: Electroencephalogram; HID-HSCT: Haploidentical hematopoietic stem cell transplantation; MRI: Magnetic resonance imaging; OS: Overall survival; PRES: Posterior reversible encephalopathy syndrome

\section{Acknowledgements}

Not applicable.

\section{Authors' contributions}

YW, TY, JH conceived and designed the experiments. YW, YZ, JR, XY, TY performed the experiments. YW, YZ, JW analyzed and interpreted the data. YW wrote the manuscript. JH critically revised manuscript. All authors read and approved the manuscript.

\section{Funding}

This study was supported by Construction Project of Fujian Medical Center of Hematology (grant number Min201704) and Startup Fund for scientific research, Fujian Medical University (grant number 2019QH1032).

\section{Availability of data and materials}

The datasets used and/or analyzed during the current study are available from the corresponding author on reasonable request.

\section{Declarations}

Ethics approval and consent to participate

The study was approved by the Ethics Committee of Fujian Medical University Union Hospital (No. 2020ky043) and waived the requirement for informed consent because the analysis was retrospective.

Consent for publication

Not applicable.

\section{Competing interests}

The authors declare that they have no competing interests.

\section{Author details}

${ }^{1}$ Department of Pediatric, Fujian Medical University Union Hospital, No. 29 Xinquan Road, Gulou District, Fuzhou City, Fujian Province, China.

${ }^{2}$ Department of Hematology, Fujian Institute of Hematology, Fujian Provincial Key Laboratory of Hematology, Fujian Medical University Union Hospital, No.

29 Xinquan Road, Gulou District, Fuzhou City, Fujian Province, China.

Received: 24 November 2020 Accepted: 23 March 2021

Published online: 01 April 2021

References

1. Xu L, Chen H, Chen J, Han M, Huang H, Lai Y, et al. The consensus on indications, conditioning regimen, and donor selection of allogeneic hematopoietic cell transplantation for hematological diseases in Chinarecommendations from the Chinese Society of Hematology. J Hematol Oncol. 2018;11(1):33. https://doi.org/10.1186/s13045-018-0564-X.

2. Lv $M$, Chang $Y$, Huang $X$. Everyone has a donor: contribution of the Chinese experience to global practice of haploidentical hematopoietic stem cell 
transplantation. Front Med. 2019;13(1):45-56. https://doi.org/10.1007/s11684017-0595-7.

3. Sun YQ, Chang YJ, Huang XJ. Update on current research into haploidentical hematopoietic stem cell transplantation. Expert Rev Hematol. 2018;11(4):273-84. https://doi.org/10.1080/17474086.2018.1447379.

4. Kurosawa S, Oshima K, Yamaguchi T, Yanagisawa A, Fukuda T, Kanamori H, et al. Quality of life after allogeneic hematopoietic cell transplantation according to affected organ and severity of chronic graft-versus-host disease. Biol Blood Marrow Transplant. 2017;23(10):1749-58. https://doi.org/1 0.1016/j.bbmt.2017.06.011.

5. Huang K, Li Y, Huang SL, Fang JP, Zhou DH, Chen C. Prophylaxis and treatment of chronic graft versus host disease. Zhonghua Er Ke Za Zhi. 2005:43:174-7

6. Hamilton BK. Current approaches to prevent and treat GVHD after allogeneic stem cell transplantation. Hematol Am Soc Hematol Educ Program. 2018; 2018(1):228-35. https://doi.org/10.1182/asheducation-2018.1.228.

7. Dulamea AO, Lupescu IG. Neurological complications of hematopoietic cell transplantation in children and adults. Neural Regen Res. 2018;13(6):945-54. https://doi.org/10.4103/1673-5374.233431.

8. Fu R, Tajima S, Suetsugu K, Watanabe H, Egashira N, Masuda S. Biomarkers for individualized dosage adjustments in immunosuppressive therapy using calcineurin inhibitors after organ transplantation. Acta Pharmacol Sin. 2019; 40(2):151-9. https://doi.org/10.1038/s41401-018-0070-2.

9. Woo M, Przepiorka D, Ippoliti C, Warkentin D, Khouri I, Fritsche $H$, et al. Toxicities of tacrolimus and cyclosporin a after allogeneic blood stem cell transplantation. Bone Marrow Transplant. 1997;20(12):1095-8. https://doi. org/10.1038/sj.bmt.1701027.

10. Koh KN, Park M, Kim BE, Im HJ, Seo JJ. Early central nervous system complications after allogeneic hematopoietic stem cell transplantation in children. Kor J Hematol. 2010;45(3):164-70. https://doi.org/10.5045/kjh.2010.4 5.3.164.

11. Faraci M, Lanino E, Dini G, Fondelli MP, Morreale G, Dallorso S, et al. Severe neurologic complications after hematopoietic stem cell transplantation in children. Neurology. 2002;59(12):1895-904. https://doi.org/10.1212/01.WNL. 0000036608.42104.B9.

12. Chohan R, Vij R, Adkins D, Blum W, Brown R, Tomasson M, et al. Long-term outcomes of allogeneic stem cell transplant recipients after calcineurin inhibitor-induced neurotoxicity. Br J Haematol. 2003;123(1):110-3. https:// doi.org/10.1046/j.1365-2141.2003.04550.x.

13. Straathof K, Anoop P, Allwood Z, Silva J, Nikolajeva O, Chiesa R, et al. Longterm outcome following cyclosporine-related neurotoxicity in paediatric allogeneic haematopoietic stem cell transplantation. Bone Marrow Transplant. 2017;52(1):159-62. https://doi.org/10.1038/bmt.2016.232.

14. Noè A, Cappelli B, Biffi A, Chiesa R, Frugnoli I, Biral E, et al. High incidence of severe cyclosporine neurotoxicity in children affected by haemoglobinopaties undergoing myeloablative haematopoietic stem cell transplantation: early diagnosis and prompt intervention ameliorates neurological outcome. Ital J Pediatr. 2010;36(1):14. https://doi.org/10.1186/1 824-7288-36-14.

15. Bartynski WS. Posterior reversible encephalopathy syndrome, part 1: fundamental imaging and clinical features. AJNR Am J Neuroradiol. 2008; 29(6):1036-42. https://doi.org/10.3174/ajnr.A0928.

16. Stevens CJ, Heran MK. The many faces of posterior reversible encephalopathy syndrome. Br J Radiol. 2012;85(1020):1566-75. https://doi. org/10.1259/bjr/25273221.

17. Yang T, Lin Q, Ren J, Chen P, Yuan X, Luo X, et al. A 5-day cytoreductive chemotherapy followed by haplo-identical hsct (FA5-BUCY) as a tumorablative regimen improved the survival of patients with advanced hematological malignancies. Oncotarget. 2016;7(48):78773-86. https://doi. org/10.18632/oncotarget.12383

18. Liu LS. 2010 Chinese guidelines for the management of hypertension. Zhonghua Xin Xue Guan Bing Za Zhi. 2011;39:579-615.

19. Chen LW, Chen JS, Tu YF, Wang ST, Wang LW, Tsai YS, et al. Age-dependent vulnerability of cyclosporine-associated encephalopathy in children. Eur J Paediatr Neurol. 2015;19(4):464-71. https://doi.org/10.1016/j.ejpn.2015.02.003.

20. Zama D, Gasperini P, Berger M, Petris M, De Pasquale MD, Cesaro S, et al. A survey on hematology-oncology pediatric AIEOP centres: the challenge of posterior reversible encephalopathy syndrome. Eur J Haematol. 2018;100(1): 75-82. https://doi.org/10.1111/ejh.12984.

21. Bartynski WS, Zeigler ZR, Shadduck RK, Lister J. Variable incidence of cyclosporine and FK-506 neurotoxicity in hematopoeitic malignancies and marrow conditions after allogeneic bone marrow transplantation. Neurocrit Care. 2005;3(1):33-45. https://doi.org/10.1385/NCC:3:1:033.

22. Zama D, Masetti R, Cordelli DM, Vendemini F, Giordano L, Milito G, et al. Risk factor analysis of posterior reversible encephalopathy syndrome after allogeneic hematopoietic SCT in children. Bone Marrow Transplant. 2014; 49(12):1538-40. https://doi.org/10.1038/bmt.2014.182.

23. Elgarten CW, Arnold DE, Bunin NJ, Seif AE. Outcomes of matched sibling donor bone marrow transplantation in children using single-agent calcineurin inhibitors as prophylaxis for graft versus host disease. Pediatr Blood Cancer. 2018;65(1). https://doi.org/10.1002/pbc.26726.

24. Zimmer WE, Hourihane JM, Wang HZ, Schriber JR. The effect of human leukocyte antigen disparity on cyclosporine neurotoxicity after allogeneic bone marrow transplantation. AJNR Am J Neuroradiol. 1998;19:601-8 discussion 9-10.

25. Uckan D, Cetin M, Yigitkanli I, Tezcan I, Tuncer M, Karasimav D, et al. Lifethreatening neurological complications after bone marrow transplantation in children. Bone Marrow Transplant. 2005;35(1):71-6. https://doi.org/10.103 8/sj.bmt.1704749.

26. Zhong ZD, Li L, Wu YH, You Y, Li WM, Zou P. Analysis of seizure risk factors after allogeneic hematopoietic stem cell transplantation: a 8 case report and literature review. J Huazhong Univ Sci Technolog Med Sci. 2013;33(5): 656-60. https://doi.org/10.1007/s11596-013-1176-x.

27. Edvinsson L, Owman C, Sjöberg NO. Autonomic nerves, mast cells, and amine receptors in human brain vessels. A histochemical and pharmacological study. Brain Res. 1976;115(3):377-93. https://doi.org/10.101 6/0006-8993(76)90356-5.

28. Gottschalk S, Cummins CL, Leibfritz D, Christians U, Benet LZ, Serkova NJ. Age and sex differences in the effects of the immunosuppressants cyclosporine, sirolimus and everolimus on rat brain metabolism. Neurotoxicology. 2011;32(1): 50-7. https://doi.org/10.1016/j.neuro.2010.10.006.

29. Luo XD, Liu QF, Ning J, Fan ZP, Xu D, Wei YQ. A clinical analysis of severe cyclosporine A-related neurotoxicity after allogenic hematopoietic stem cell transplantation. Zhonghua Nei Ke Za Zhi. 2008;47:40-3.

30. Roth C, Ferbert A. Posterior reversible encephalopathy syndrome: long-term follow-up. J Neurol Neurosurg Psychiatry. 2010;81(7):773-7. https://doi.org/1 0.1136/jnnp.2009.189647

31. Bartynski WS, Boardman JF. Distinct imaging patterns and lesion distribution in posterior reversible encephalopathy syndrome. AJNR Am J Neuroradiol. 2007;28(7):1320-7. https://doi.org/10.3174/ajnr.A0549.

32. Fischer M, Schmutzhard E. Posterior reversible encephalopathy syndrome. J Neurol. 2017;264(8):1608-16. https://doi.org/10.1007/s00415-016-8377-8.

33. Magnasco A, Rossi A, Catarsi P, Gusmano R, Ginevri F, Perfumo F, et al. Cyclosporin and organ specific toxicity: clinical aspects, pharmacogenetics and perspectives. Curr Clin Pharmacol. 2008;3(3):166-73. https://doi.org/1 $0.2174 / 157488408785747674$

34. Masetti R, Cordelli DM, Zama D, Vendemini F, Biagi C, Franzoni E, et al. PRES in children undergoing hematopoietic stem cell or solid organ transplantation. Pediatrics. 2015;135(5):890-901. https://doi.org/10.1542/ peds.2014-2325

35. Karia SJ, Rykken JB, McKinney ZJ, Zhang L, McKinney AM. Utility and significance of gadolinium-based contrast enhancement in posterior reversible encephalopathy syndrome. AJNR Am J Neuroradiol. 2016;37(3): 415-22. https://doi.org/10.3174/ajnr.A4563.

36. Gleeson JG, du Plessis AJ, Barnes PD, Riviello JJ Jr. Cyclosporin a acute encephalopathy and seizure syndrome in childhood: clinical features and risk of seizure recurrence. J Child Neurol. 1998;13(7):336-44. https://doi.org/1 0.1177/088307389801300706.

37. Bartynski WS. Posterior reversible encephalopathy syndrome, part 2: controversies surrounding pathophysiology of vasogenic edema. AJNR Am J Neuroradiol. 2008;29(6):1043-9. https://doi.org/10.3174/ajnr.A0929.

38. Servillo G, Bifulco F, De Robertis E, Piazza O, Striano P, Tortora F, et al. Posterior reversible encephalopathy syndrome in intensive care medicine. Intensive Care Med. 2007;33(2):230-6. https://doi.org/10.1007/s00134-006-0459-0.

39. Ayas M, Al-Jefri A, Al-Seraihi A. In cyclosporine induced neurotoxicity, is tacrolimus an appropriate substitute or is it out of the frying pan and into the fire? Pediatr Blood Cancer. 2008;50(2):426author reply 7. https://doi. org/10.1002/pbc.21211.

\section{Publisher's Note}

Springer Nature remains neutral with regard to jurisdictional claims in published maps and institutional affiliations. 